Article submitted to

Annual Reviews of Materials Science

\title{
Thin Film Synthesis by Energetic Condensation
}

\author{
Othon R. Monteiro \\ (1) Lawrence Berkeley National Laboratory, University of California, \\ Berkeley, California 94720
}

November 2000

Contact Author: $\quad$ Dr. Othon R. Monteiro Lawrence Berkeley National Laboratory

Mail Stop 53-004

One Cyclotron Rd.

Berkeley, CA 94720 USA

e-mail: ORMonteiro@lbl.gov

FAX: (510) 486-4374

This work was supported by the U.S. Department of Energy, under contract No. DE-AC03-76SF00098. 


\section{THIN FILM SYNTHESIS BY ENERGETIC CONDENSATION}

Dr. Othon R. Monteiro

Lawrence Berkeley National Laboratory

Mail Stop 53-004

One Cyclotron Rd.

Berkeley, CA 94720 USA

e-mail: ORMonteiro@lbl.gov

FAX: (510) 486-4374

Phone: (510) 486-6159

\section{Abstract:}

The use of energetic particles (ions and atoms) has become increasingly important in physical vapor deposition techniques. These deposition processes can be divide in two main classes: Ion beam assisted deposition and energetic condensation (or deposition). This article focusses on the latter, i.e. processes in which the actual depositing species have energies that far exceed ordinary thermal energies, namely energies greater than 20 $\mathrm{eV}$. The phenomenology of the effect of these high energy particles on the growth of thin films is first presented in general and then specific examples of film deposition are presented. The examples drawn here are of films that have been prepared by Metal Plasma Immersion Implantation and Deposition. The observed microstructures and functional properties of these films are discussed in terms of processing conditions.

Key words: thin film, ion-assisted depositon, energetic condensation 


\section{Contents:}

1.0 Introduction

2.0 Role of Energetic Depositing Species:

2.1 On Adsorption and Adhesion

2.2 On Surface Mobility

2.3 On Texturing

$2.4 \quad$ On Stress

2.5 On Substrate Temperature Evolution

3.0 Deposition Process

4.0 Films

4.1 Non-hydrogenated Amorphous Carbon Films

4.2 Metal containing DLC and Metal Carbides

4.3 Multilayers

5.0 Summary

6.0 Acknowledgments

7.0 References 


\subsection{Introduction:}

The microstructure and properties of films strongly depend on the deposition process and process conditions used(1-5). In physical vapor deposition the major process control parameters are substrate temperature, background gas pressure, and energy, flux and angle of incidence of the depositing particles (atoms and/or ions). Ordinary microstructures of coatings produced by PVD are usually described by maps, as a function of deposition process parameters (also referred to as Zone Models)(2, 6, 7). Movchan and Demchishin(6) proposed a zone model to describe the microstructure of thick evaporated coatings, according to which, three different types of morphologies can result depending on the substrate temperature relative to the melting temperature of the film material $\left(\mathrm{T} / \mathrm{T}_{\mathrm{m}}\right)$. At the lowest temperatures the film assumes a columnar structure with a high density of voids in the grain boundaries (zone $1-\mathrm{T} / \mathrm{T}_{\mathrm{m}}<0.3$ ). At higher temperatures, surface diffusion becomes relevant, resulting in densification of grain boundaries (Zone $2-0.3<\mathrm{T} / \mathrm{T}_{\mathrm{m}}<0.5$ ). When bulk diffusion becomes important, the film consists of equiaxial grains (Zone $3-\mathrm{T} / \mathrm{T}_{\mathrm{m}}>0.5$ ). Thornton(2) extended this zone model to films produced by magnetron sputtering, and included the Ar pressure as another parameter. In addition to the three zones proposed by Movchan and Demchishin(1, 6), Thornton identified a transition zone (T) between zones 1 and 2 consisting of a dense array of poorly defined fibrous grains.

The use of energetic ions or neutral species for the deposition of thin films has become increasingly important in recent years $(8,9)$. A different Zone Model was conceived to describe microstructures of films produced by processes that include energetic particles $(7,10,11)$. The inclusion of ion energy in this new Map, makes the 
stability domain of the Zone T to increase with increasing particle energy(7) (Figure 1). Those Zone Models were developed for polycrystalline films. However it is well know that large doses of high-energy ions lead to amorphization. Energetic ions also have a significant effect on the microstructure and properties of amorphous films. For instance, density, intrinsic stresses, and chemical state have all been correlated to the incident energy flux.

This article presents and discusses several aspects of the synthesis of films when the depositing species have energy in the range of approximately $20 \mathrm{eV}$ to a few $\mathrm{keV}$. In this energy range, incident ions and atoms can dislodge adsorbed species and penetrate the substrate surface. This may lead to the film growing beneath the surface(12-14), in a process that became known as sub-plantation. Sub-plantation has been used to describe formation of several materials, in particular non-hydrogenated diamondlike carbon films (DLC). This article will focus on processes and films in which the energetic species are constituent of the films. Such processes are generically referred as Energetic Deposition. It does not include conventional ion beam assisted deposition (IBAD). Typically in IBAD, an ion source is responsible for supplying the inert gas ion whose main purpose is to transfer energy to the growing film. The actual film material originates from a different source. In particular, the films described here were produced by Metal Plasma Immersion Ion Implantation and Deposition (MePIIID)(15, 16). Although I will be focussing on one particular deposition process, the phenomenology discussed here can be extended to other processes that make use of hyperthermal precursors, such as pulsed laser deposition. 
The remaining of this monograph will be divided in the following parts. In section 2 , a qualitative discussion of the impact of ion bombardment and quenching on the several steps of the deposition process is presented. Section 3 will briefly introduce the deposition technique used to prepare the films shown as examples in the latter sections. Section 5 contains examples of films prepared using this technique, and discusses the role of energetic ions in each case. The article closes with a summary of the beneficial role of energetic ions on thin film deposition. 


\section{Role of Energetic Depositing Species:}

\section{1 On Adsorption and Adhesion}

For background pressure greater than $10^{-8}$ Torr, the substrate surface in any PVD process consists of adsorbed species that saturate the surface bonds and hinder direct bonding between the deposited film and the substrate(9). A common procedure to remove impurities from the surface, sputter cleaning, when carried out immediately before starting the deposition is not always effective, because the time interval between surface cleaning and starting the deposition is usually long enough to guarantee complete monolayer coverage of the substrate. Moreover, sputter cleaning can cause surface amorphization for some substrates.

This situation may be improved when the deposition is carried out at elevated temperatures, which promotes desorption of impurities, or if the depositing species carry enough energy to break through this adsorbed layer. High-energy species can simply dislodge adsorbed atoms, or they can be incorporated below the substrate surface. Ion energies greater than $25 \mathrm{eV}$ will typically suffice to promote desorption of physisorbed impurities, as well as some sub-surface implantation. Since adhesion between coating and substrate is greatly affected by the presence of impurities at the interface, the use of energetic ions can greatly enhance adhesion.

During energetic deposition, adhesion can be improved by using high-energy ions during the early stages of deposition. Usually at higher energies than those used during the later stages. At these energies, the incident ions penetrate through the depositing film into the 
substrate. This ion implantation produces dense trails of ionization and direct collisional displacement of the substrate atoms. The random disruption of electronic bonding and short-range atomic displacements produced at the interface can lead to the formation of fresh bonds across the interface. This process is known as "ion stitching”(17, 18).

Figure 2(a) shows a high resolution image of the interface between a $t a-C$ (DLC) film and (100) Si substrate. This interface was produced during the deposition of a $t a-\mathrm{C}$ by applying a substrate bias voltage of $-2 \mathrm{kV}$, with a duty cycle of $25 \%$. Monte-Carlo simulation $(19,20)$ of a deposition process carried out under these conditions were performed using t-dyn, and the results are shown in Figure 2(b). The observed interface roughness, as measured by the width of the transition region between the crystalline Si and the amorphous $\mathrm{C}$ is much thinner than the projected range for $\mathrm{C}$, and only extends over 4 or 5 lattice fringes $(<1 \mathrm{~nm})$. However, damaged regions well into the $\mathrm{Si}$ can be observed, as regions with disturbed fringe periodicity.

\subsection{On Surface Mobility}

Another important parameter that defines the microstructure resulting from PVD processes is adatom surface mobility. Surface mobility is a thermally activated process. There is a direct correlation between surface mobility and the energy of the impinging ion for two fundamental reasons: the momentum transfer onto the lattice as well as the formation of surface defects. It is not easy to establish a quantitative description of the effect of depositing energetic particles on adatom mobility, or even on sub-surface mobility. Seitz and Koehler(21) have estimated the maximum radial distance $r$ ' that an 
atom can migrate on a surface as a temperature spike is imposed on a surface as being given by:

$$
r^{\prime}=\frac{4}{(324 \pi)^{1 / 6}}\left(\frac{E}{Q}\right)^{1 / 3} r_{s}
$$

where $E$ is the energy transferred from the incident atom to the film, $Q$ is the activation energy for adatom diffusion, and $r_{s}$ is the atomic radius, which can be approximately given by $\alpha k T_{M}$, where $\alpha$ is a proportionality constant approximately $5, k$ is the Boltzmann constant and $T_{M}$ is the melting temperature of the material being deposited. The power dependence of $r$ ' on $E$, suggests that even for depositing species with energies of hundreds of $\mathrm{eV}$ (which is the range of energies that qualify for energetic deposition), the mobility radius should not exceed 10 to 15 times $r_{\mathrm{s}}$.

\subsection{On Texturing}

Another very important film characteristic that is strongly affected by ion energy is the film texture $(8,22-24)$. During deposition, texturing (preferential orientation of grains in one or several crystallographic directions) may be thermodynamically or kinetically controlled. Thermodynamically controlled texturing will take place when there is surface energy anisotropy and there is enough adatom mobility so that equilibrium can be attained. Based on the discussion on Section 2.2, ion energy does not have great impact on surface mobility, and therefore thermodynamic control requires elevated deposition temperatures. Kinetically controlled texturing will occur if for instance the deposition rate on certain facets is higher than on others due to difference in sticking coefficients. This of course does not apply for amorphous films. In ion assisted deposition or in energetic 
deposition there is still yet another cause for preferential growth directions: differences in sputtering yields among the various crystallographic directions. For instance, crystallographic directions that allow channeling will have intrinsically lower sputtering yields, and therefore will be favored in such deposition processes. Yet another cause for texturing is the presence of stresses during deposition(25-27), and as it is discussed next, ion bombardment plays a very important role in stress evolution in thin films.

\subsection{On stress}

Coatings prepared by processes that make use of non-energetic particles (e.g. evaporation) are in general under tensile stresses (28). On the other hand when energetic particles are used the resulting film is often under compressive stresses. Sputter deposited films, which make use of atoms with low energy (in general $2-5 \mathrm{eV}$ ), can have either compressive or tensile stresses depending on the background gas. Since such films are not being discussed here, I will refrain from any further discussion on these.

When energetic ions are used, either in IBAD or in energetic deposition processes, compressive stresses are frequently observed. Typical dependence of intrinsic stresses in polycrystalline and amorphous films are shown in Figure (3). At very low energies, the tensile stresses in polycrystalline films result from coalescence of the film through regions with density less than ideal, such as grain boundaries(29). Increasing energy increase the density at grain boundaries, eliminating the source of tensile stress. Density fluctuations in amorphous films, due for instance to self shadowing, may account for tensile stresses in amorphous films produced at very low energies. The cross-over point 
(zero-stress) for amorphous films occurs at very small normalized energies, namely a few electron-Volts(30).

In energetic deposition, the generation of compressive stress is attributed to the excessive concentration of interstitials, which are produced by direct or recoil implantation, or to ion penning, i.e. lattice distortion resulting from energetic particles striking film $(31,32)$. At very low ion energies, interstitial formation can occur without the simultaneous formation of vacancies. As the ion energy increases, Frenkel pairs (vacancy-interstitial) become the predominant defects. As long as the net concentration of interstitials is greater than that of vacancies, the intrinsic stresses will be compressive in nature. (for the sake of clarification, interstitial sites in an amorphous film are those with smaller mean site volume than the sites in an amorphous film having no voids(9)). When the ion bombardment is carried out with ions of non-reactive gases, some incorporation of gas may take place. There will be greater tendency for those ions to be lost to the environment, and therefore the level of intrinsic stresses in such films is expected to be lower (less compressive) than the level of stresses encountered in films produced by energetic condensation.

\subsection{On Substrate Temperature Evolution}

The energy flux onto the substrate during energetic deposition processes can be quite high, and it is not unreasonable to expect that there will be temperature fluctuations of at the substrate. Temperature here refers to a macroscopic temperature at the surface of the substrate, and not to individual thermal spikes common to ion implantation. Even in 
actively cooled substrates, the temperature increase may be high enough to cause modification of the films.

The surface temperature of a energetic deposition process consisting of alternating periods of high and low ion energy deposition was estimated by carrying out an energy balance on the substrate, schematically shown in Figure 4. Heat loss through the sides of the substrate is neglected because the substrate is considered thin, as is the case in $\mathrm{Si}$ wafers. The heat input is determined by the ion current density $i_{\text {ion }}$ and the energy of the depositing ions $E_{\text {ion }}$, which depends on the bias voltage and duty cycle.

The substrate temperature will satisfy:

$$
\rho c_{p} \frac{\partial T}{\partial t}=\nabla \cdot k \nabla T
$$

where $\rho$ is the density, $c_{p}$ is the specific heat, $T$ is the temperature, $k$ is the thermal conductivity of the substrate (assumed here to be the same as that of the film for the sake of simplicity) and $t$ is time. The boundary conditions at the backside of te substrate is:

$$
-k \frac{\partial T}{\partial t}=h_{c} A \mathbf{D}_{-}-T_{h o l d e r} \text { ! }
$$

where $T_{b}$ is the temperature at the backside of the wafer, and $T_{\text {holder }}$ is the temperature of the holder surface in contact with the substrate, which is assumed to remain constant since the substrate holder usually consists of a metal block directly cooled with water. $h_{c}$ is the heat transfer coefficient between two solid surfaces in direct contact. 
The boundary condition at the film surface is

$$
-k \frac{d T}{d x}=q_{\text {plasma }}
$$

where $q_{\text {plasma }}$ is periodic because of the pulse-biased substrate: $q_{\text {on }}$ during the time that the bias voltage is applied to the substrate $\left(t_{o n}\right)$ and $q_{\text {off }}$ during the time that the voltage is not applied $\left(t_{o f f}\right)$. For the sake of simplicity, the temperature gradient in the substrate is assumed negligible. This is a good assumption for thin substrates with high thermal conductivity, as is the case with thin $\mathrm{Si}$ wafers. Under these conditions there is in fact an analytical solution for the temperature at the end of an arc pulse $n_{p}$ :

$$
T_{n_{p}}=T_{\text {holder }}+e^{-\alpha t_{o n}} e^{\alpha t_{o f f}}+\frac{q_{o f f}}{h_{c}} \mathbb{0} e^{-\alpha t_{o f f}}
$$

where $n_{p}$ is the number of pulses and $\alpha=h_{c} A / \rho c_{p} V, A$ is the surface area and $V$ the substrate volume.

The treatment of the heat load due to ion bombardment as a surface heat flux is justified(33) by noticing that the implantation depth for the ordinary enegy used in MePIIID (less than $5 \mathrm{keV}$ ) is significantly less than a significant "thermal depth" $l$, i.e. the length over which there is a significant temperature change in time $t$, where $l$ is defined by:

$$
l=\sqrt{\frac{k}{\rho c_{p}} t}
$$




\subsection{Deposition Process}

The films described in the next section were prepared by Metal Plasma Immersion Ion Implantation and Deposition (MePIIID). In this process, a plasma stream is produced by a cathodic arc plasma source(34), and directed towards the substrate via a quarter torus macroparticle filter. Cathodic arc sources are known for producing large quantities of macroparticles - molten droplets of cathode material - which need to be eliminated in order to obtain high quality films. Macroparticles that are co-deposited on the film result in phase heterogeneity, and affect negatively the film properties. Compound films (consisting of more than one species) were prepared either by using multiple plasma sources $(35,36)$, or by carrying out the deposition in the presence of a reactive gas $(15$, 36).

The substrate is repetitively pulse-biased to a negative voltage. During the periods that the bias voltage is off, plasma ions stream towards the substrate with relatively low energies (up to about $200 \mathrm{eV}$ depending on the species), where they can condense or be implanted at very shallow depths. The native energy of this streaming plasma is a function of the ion species $(15,37)$ and the gas pressure in the chamber(38, 39). During the periods that the bias voltage is on, a high voltage sheath rapidly forms at the substrate-plasma boundary, and plasma ions are accelerated through the sheath and into the substrate. Therefore during film growth there are alternating periods of high-energy ions and periods of low-energy ions or atoms. 
A schematic diagram of the apparatus used to generate the plasma beam is shown in Figure 5 with only one plasma source(35). The plasma source was a vacuum arc minigun(34), consisting of cathode, anode and focusing coil. Each mini-gun has a $90^{\circ}$ filter to separate the plasma stream from macroparticles and neutrals. Filtering is particularly important during the formation of compound films in order to assure complete reaction between the constituents. This source typically operates with arc current between 150 and $250 \mathrm{~A}$, pulse duration up to $10 \mathrm{~ms}$ and repetition rate of $2 \mathrm{~Hz}$.

The microstructure and composition of the films were characterized by a variety of tools. Rutherford backscattering spectrometry using $1.8 \mathrm{MeV} \mathrm{He}^{+}$ions was the primary tool for compositional analysis. High-resolution transmission electron microscopy was carried out on a Topcon 002B TEM to characterize the films and interfaces microstructure. Scanning electron microscopy on a JEOL SEM Model 6400 was used to study the film morphology. Internal stresses in the films were calculated from the change in curvature radius of the Si substrate, measured with a Tencor FLX-2320 Stress Measurement Instrument. Si wafers with 3" dia. were used for those measurements. Film hardness was determined by a nanoindentation technique using a Hysitron Picoindenter with loads in the range of $0-250 \mu \mathrm{N}$. Surface roughness of the films war measured on (100) $\mathrm{Si}$ substrates with a Park T5 SPM in tapping mode.

A combined energy parameter was defined by Musil et al.(40) as the average energy carried by arriving ions per condensing particle, which in mathematical terms is expressed by: 


$$
E_{P}=\frac{E_{o n} * J_{o n}+E_{o f f} * J_{o f f}}{J_{o n}+J_{o f f}}=E_{o f f}+\left[E_{o f f}+\langle q\rangle * V_{b i a s}\right] * \frac{J_{o n}}{J_{o n}+J_{o f f}}
$$

where $E_{o n}$ and $E_{o f f}$ are the energies of the depositing ions during the on-time and off-time of the pulse bias respectively; $J_{\text {on }}$ and $J_{\text {off }}$ are the total ion flux arriving at the substrate during the on-time and off-time of the pulse bias respectively. $V_{\text {bias }}$ is the applied bias voltage, and $\langle q\rangle$ is the mean charge state. By assuming that the integrated fluxes are proportional to the duration of the pulses, this expression can be approximated by

$$
E_{P}=E_{o f f}+\left[E_{o f f}+\langle q\rangle * V_{\text {bias }}\right] * \frac{t_{o n}}{t_{o n}+t_{o f f}}
$$

The use of a combined energy parameter has been useful in some events to predict the film microstructure(40). However, it does not include the total rate of deposition and therefore is not appropriate to fully describe changes in microstructures in thin films that may result from energy flux. This is particularly important in the case of DLC prepared by MePIIID, where the rate of arrival of incident ions has a significant impact in the final properties of the film because of localized thermal effects, as is demonstrated in the next Section.

\subsection{Films}

\subsection{Non-hydrogentated amorphous carbon films:}

Non- hydrogenated amorphous carbon films with high content of $\mathrm{sp}^{3}$-hybridization (DLC) have been synthesized by a variety of different methods including Pulsed Laser Deposition (PLD)(41-43), Filtered Cathodic Arc (FCA)(16, 44-47) and Mass Selected 
Ion Beam (MSIB)(48, 49). A common feature in these processes is that the film is produced from incident $\mathrm{C}^{\mathrm{n}+}$ ions with energies above $20 \mathrm{eV}$, a threshold for the $\mathrm{C}^{+}$ions to penetrate the surface of the growing film $(50,51)$. When the deposition parameters are optimized, such processes can produce films with $\mathrm{sp}^{3}$ content as high as $85 \%$ resulting in amorphous carbon films with properties approaching that of crystalline diamond $(52,53)$. As the energy flux into the growing film increases, either by increasing the ion energy or the ion flux, conversion of $\mathrm{sp}^{3}$ into $\mathrm{sp}^{2}$ bonded carbon occurs due to a localized increase in temperature or interaction between cascades.

There is a direct correlation between the density, hardness, level of intrinsic stresses and the $\mathrm{sp}^{3}$ content in DLC films $(46,51,53,54)$. The as-deposited DLC films with highest $\mathrm{sp}^{3}$ content have very high levels of intrinsic stresses, above $10 \mathrm{GPa}$, which limits the deposition to thickness between 100 and $200 \mathrm{~nm}$ before delamination happens(54-56). In order to produce thicker DLC films, Anders and co-workers used an initial step(16), which promotes intermixing between the film and the substrate, as discussed in Section 2.1. Another alternative is the use of a reactive intermediate layer. Nevertheless, both these approaches have failed to produce films thicker than $500 \mathrm{~nm}$ because of the very high compressive stresses.

Other alternatives that have been suggested to produce thicker films focussed on relaxing the intrinsic. Those include annealing of DLC films(57-60), formation of multilayers(54, $61,62)$ or incorporation of other elements $(35,63)$. Those procedures will be discussed later on in this review. 
Deposition of DLC provides a good example of the difference between energetic deposition or condensation and IBAD-like process. Despite several attempts to produce DLC films using IBAD techniques(64-67), properties like hardness (max around 20 $\mathrm{GPa}$ ), intrinsic stresses (max around $2 \mathrm{GPa}$ ) and density are significantly lower than those in DLC films with high $\mathrm{sp}^{3}$ content, which are prepared with energetic $\mathrm{C}^{\mathrm{n}+}$ ions.

In principle, one could expect that the two deposition processes would be equivalent, and therefore produce similar films. In the energetic deposition, the energetic ion arrives and penetrates the surface of the substrate transferring its energy into the lattice. In the IBAD process, energetic ions bombard and penetrate the surface transferring momentum to the atoms on the surface, which by-recoil implantation are also transported into the lattice. In the latter case, the incident ion does not participate in the growth. Whether one accepts the McKenzie model(45) that $\mathrm{sp}^{3}$ bond stabilization results from high intrinsic stresses or the Lifshitz(48)-Robertson(52) that such stabilization results from high film density, the phenomenological distinction between those two deposition processes should explain the difference between the products. According to the presentation in Section 2, the most striking difference between the two processes above is the presence of inert gas atoms in IBAD process. Loss of those atoms to the environment may result in reduction of density and intrinsic compressive stresses, thus reducing the driving force for the formation of $\mathrm{sp}^{3}$ bonds. 
DLC films prepared by filtered cathodic arc and ion beam tend to be very $\operatorname{smooth}(68)$ because of the absence of macroparticles, enhanced surface mobility and self-sputtering. On the other hand, films prepared by pulsed laser deposition tend to be slightly rougher, which may in part be attributed to the presence of particulates. An AFM image of a 50 $\mathrm{nm}$ thick $t a-\mathrm{C}$ film deposited on (100) Si substrate resulted to a $\mathrm{R}_{\mathrm{rms}}$ of $0.1 \mathrm{~nm}$, which is comparable to the bare Si surface. A cross-section image of such a film is shown in Figure 2. The image contrast of the amorphous film indicates that no turbostratic structure is present in the DLC film, typical of energetically deposited DLC films.

The film properties are strongly dependent on the ion energy and on the ion energy flux. A recent compilation of the effect of ion energy on the properties of film prepared with filtered cathodic arc has been published(69), and from those data, I plot the film density versus the ion energy in Figure 6. The intrinsic stress in DLC film follow a curve with similar shape as that for density, namely, the stress increases up to about $10 \mathrm{GPa}$ with increasing the applied bias voltage, and after about $-100 \mathrm{~V}$, it begins to decrease. The decrease in stresses with increasing voltage beyond $100 \mathrm{~V}$ (for FCA) is related to increasing film local (thermal spikes) and global temperature due to the energy flux onto the substrate. The latter phenomenon explains the difference between the observed dependence of stress in DLC films on the ion energy and the generic behavior shown in Figure (3).

Early in the development of DLC, Cuomo et al(70) have shown the important effect of substrate temperature on the film properties. This was demonstrated by using substrates 
with remarkably different thermal conductivity, and by carrying out the deposition at ambient and liquid nitrogen temperatures. For the pulsed cathodic arc deposition system, the effect of the arc pulse duration and duty on the film temperature was estimated for the deposition conditions used in LBNL and correlated to the film properties. Equation (5) was used to calculate the temporal evolution of the temperature for different conditions, and the results are plotted in Figure 7 A major uncertainty in this model is the value of the heat transfer coefficient $h_{c}$ between two solid surfaces, but for low substrate temperatures, a sensitivity analyses demonstrated that its impact is not strong. According to the curves in Figure 7, little change is expected in film properties for low applied bias voltages or thin films, but for bias voltages of $-2000 \mathrm{~V}$ some change due to temperature should be expected. The hardness of the DLC films prepared at these same conditions are plotted in Figure 8. The hardness of samples prepared using the low bias voltage was not dependent on the total thickness of the film, and therefore on the total deposition time. On the other hand, for the samples prepared at high bias voltage, there was a noticeable decrease in hardness of the thicker films. This dependence fits well with the thermal history of the samples, which are plotted in Figure 7. This confirms the observations that substrate temperature about $150^{\circ} \mathrm{C}$ are enough to promote significant reduction of the $\mathrm{sp}^{3}$ content $(51)$.

Recently it has been speculated that surface charge accumulation may lead to a thickness dependent structure in amorphous carbon films(71). This argument cannot be used here, because a decrease in the electric field as a consequence of increasing film thickness 
would in fact lead to harder DLC instead of softer, and therefore would be the opposite of what is experimentally observed (Figure 8).

Intrinsic stresses of the $t a-\mathrm{C}$ films can be significantly relaxed by thermally annealing the films without a significant loss of the diamondlike properties of the film(57, 59, 60, 7274). This provides an important path for the production of thick DLC films(58), which is critical to extend the range of applications of this material.

\subsection{Metal containing DLC and Metal Carbides}

Energetic condensation has also been very useful in producing metal containing DLC films in a very large composition range( $35,62,75-78)$, namely from a few ppm to stoichiometric metal carbides. The original motivation of adding refractory metals to DLC films was threefold: to increase the chemical and thermal stability of the films, to modify surface properties of the films, and to decrease internal stresses. Although DLC films can be annealed at temperatures up to $700^{\circ}$ in high vacuum $(57,59)$ without noticeable change in properties, thermal stability in air or in other oxidative environments is not as good.

Filtered cathodic arc was used to prepare silicon doped DLC films (DLC:Si) using the dual-source approach described in Section 3: one Si plasma source and one C plasma source. Films with Si content from 1 at $\%$ to 7 at $\%$ were fully amorphized, and showed no evidence of segregation at the surface, at the film-substrate interface or in domains within the film. Those films were tested for wear at very high rotation speeds $(\approx 35000 \mathrm{rpm})$ in 
air and in absence of lubrication. The DLC:Si with 7 at\% silicon showed a remarkable improvement in performance (here measured as the time until failure) at $300^{\circ} \mathrm{C}$, when compared to the undoped DLC film or to uncoated parts. The exact reason for the enhancement of lifetime is not fully understood. Si incorporation in hydrogenated a-C films increase the $\mathrm{sp}^{3}$ content(79), but the same reasoning cannot be extrapolated to undoped non-hydrogenated films because the $\mathrm{sp}^{3}$ content in the latter is already high. However, it is well known that $\mathrm{SiC}$ is much more resistant to oxidation at elevated temperatures than DLC. At high temperatures, $\mathrm{SiC}$ forms a $\mathrm{SiO}_{2}$ layer that precludes further diffusion of oxygen into the SiC. A similar mechanism could prevail here because even at such low Si contents. If the Si content increases beyond 20 at $\%$, amorphous silicon carbide, which is softer than DLC:Si, is produced, and the performance decays(79).

Carbides of transition metals are of great interest in the field of tribological application due to their hardness and wear resistance(80). Among the carbides, TiC is of particular importance. Titanium carbide combines the advantages of a high melting point $\left(3140^{\circ} \mathrm{C}\right)$ and hardness with those of a relative lightness (density $4.93 \times 10^{3} \mathrm{~kg} \mathrm{~m}^{-3}$ ). It also exhibits high resistance to both corrosion and high temperature oxidation, and has a relatively low friction coefficient.

$\mathrm{TiC}$ has a $\mathrm{NaCl}$ face-centered cubic structure (space group $\mathrm{Fm} 3 \mathrm{~m}$ ) with lattice parameter $0.43274 \mathrm{~nm}(81)$. This structure can be visualized with the Ti atoms occupying a fcc lattice and $\mathrm{C}$ atoms occupying the octahedral interstices. TiC phase extends through a 
relatively large solubility range at room temperature, from 40 to $50 \mathrm{C}$ at. $\%$, i.e. a significant amount of $\mathrm{C}$ vacancies can be present without disrupting the stability of the compound.

Figure 9 shows a bright-field transmission electron image of the as-deposited DLC:Ti with a low Ti content. The microstructure of DLC:Ti (or $\mathrm{Ti}_{\mathrm{x}} \mathrm{C}$, with $0<\mathrm{x}<1$ ) consisted of a mixture of an amorphous carbon with a $\mathrm{TiC}$ crystalline phase. The $\mathrm{TiC}$ was predominantly nanocrystalline and the grain size increases with increasing $\mathrm{Ti}$ content. The solubility range in $\mathrm{TiC}$ is quite large, and therefore the excess $\mathrm{C}$ in $\mathrm{Ti}_{\mathrm{x}} \mathrm{C}$ was either accommodated as interstices in the B1 structure, or led to the formation of amorphous diamond-like carbon (DLC)(77). A high resolution image of the a nanocrystalline $\mathrm{Ti}_{\mathrm{x}} \mathrm{C}$ film with $x \approx 1$ is shown in Figure 10 .

Transmission electron diffraction patterns of titanium carbon films prepared with two $\mathrm{Ti}$ concentrations are shown in Figure 11. The films with the highest content of $\mathrm{Ti}$ were strongly textured with the film normal around a $<002>$ zone axis. As the Ti content decreases, the films become less textured, and the electron diffraction pattern becomes more ring-like, consistent with the decrease in grain size and loss of preferential orientation. Sputter deposited TiC films have shown strong texturing along <111>, instead of <002> observed here(82). This difference may be attributed to differences in the ion energies, since in sputter deposition, the depositing particles have very low energies. 
Loss of film texture for increasing carbon content can result by either of two mechanisms. The first is that the formation of an amorphous carbon network (DLC) disperses the titanium carbide grains, favoring constant re-nucleation of carbide particles as the film thickness increases; the second is related to the energy transferred to the growing film by the ions. Vacuum arc plasmas are known to generate multiply ionized species with average ion charge state that depends on the cathode elements. The mean ion charge states for titanium and carbon are 2.1 and 1.0, respectively, which for a given bias voltage would lead to a higher deposited energy. Therefore we expect a greater mobility of the surface atoms when the ion flux is titanium rich, and at the same time a greater sputtering yields of the non-channeling directions. Texturing of ion assisted e-beam evaporated $\mathrm{TiC}$ was recently reported(83). Their results indicated that for low temperature a $\langle 111>$ texture prevails and at elevated temperature the $<002>$ texture prevails.

Another refractory metal carbide of interest is WC, because of its mechanical and tribological properties at ambient and elevated temperatures. Energetic deposition is a successful tool to produce films of carbon-tungsten with a variety of composition(78, 84, 85), spanning from 1 at $\%$ to 50 at $\%$.

In a DLC:W film, a $\mathrm{C}$ atom may be bonded to another $\mathrm{C}$ atom or a $\mathrm{W}$ atom. For the same overall $\mathrm{W}$ content, the amount of carbidic bonds, i.e. W-C bonds, increases with increasing the incident ion energy(85). This behavior was demonstrated by comparing the intensity of the carbidic peak in X-ray Photoelectron Spectra of films prepared with 
voltages from $-100 \mathrm{~V}$ to $-2000 \mathrm{~V}$. Carbide formation is favored by high temperature, and here, it may result from either an increase in the cascade volume, or the macroscopic temperature increase (as described in section 2). Contrary to the observations for TiC, the structure of the DLC:W films with W content below 20 at\% was amorphous. Films with higher W content were primarily nanocrystalline without any specific texture. The WC phase was dispersed in the amorphous carbon phase. Electron diffraction patterns for DLC:W with 20 at $\% \mathrm{~W}$ and another with 10 at\% are shown in Figure 12(85). For high W contents, the crystalline phase was $\beta$-WC, contrary to previously reported(85)

Hardness and the intrinsic stresses of DLC:W are plotted as a function of ion energy (bias voltage) and $\mathrm{W}$ content in Figures 13 and 14 respectively(85). Small additions of W led to significant decrease in the intrinsic stresses and a simultaneous increase in hardness for all but the hardest of the DLC films. The decrease in intrinsic stress with increasing the $\mathrm{W}$ content can be explained on a pure energetic basis. The mean charge state of $\mathrm{W}$ is 3.1 , as opposed to 1 for $\mathrm{C}$, and this results in a net energy flux increase.

The dependence of hardness on the W content is complex. Hardness of undoped nonhydrogenated DLC and $t a-C$ films results from a balance between the formation of $\mathrm{sp}^{3}$ hybridization due to local increases in mass density of the film, and lattice relaxation due to thermal spikes $(52,86)$. The maximum hardness of these films was found to occur at a bias voltage of around $-100 \mathrm{~V}$, which coincides with the maximum $\mathrm{sp}^{3}$ content and corresponds to $\mathrm{C}^{+}$ion energy around $100 \mathrm{eV}(46,52,53,86)$. When a bias voltage of -100 $\mathrm{V}$ is applied to a substrate exposed to a $\mathrm{C}^{+}$and $\mathrm{W}^{\mathrm{n}+}$ plasma stream, the average ion 
energy is approximately $120 \mathrm{eV}$ and $410 \mathrm{eV}$ respectively because of their charge state distribution and native energies. Therefore, addition of $\mathrm{W}$ to the plasma stream and to the film results in two competing effects: (a) the larger size of $\mathrm{W}$ atoms when compared to $\mathrm{C}$ atoms leads to greater increases in local density and in intrinsic stress; and (b) the presence of multiple charged ions in the plasma stream leads to greater energy transfer to film, which favors annealing. The final effect on the film hardness is a compromise between these two effects.

\subsection{Multilayers}

Oftentimes a monolithic film will not have the combination of properties to make it acceptable for a particular application. In these cases, a viable alternative is the use of multilayers, which may result in a combination of properties that best suits the application(87). A typical example is ta-C which has very high intrinsic stresses. In order to build thick ta-C films Anders(88) suggested a multilayer of alternating soft and hard phases of amorphous carbon, prepared by filtered cathodic carc, with bias voltages of $2000 \mathrm{~V}$ and $-100 \mathrm{~V}$ respectively. The reduction in intrinsic stress obtained was greater than would be expected by the Rule of Mixtures, and the final film was still extremely hard.

Energetic deposition is very suitable for the production of multilayer structures. It can be used at room temperatures, which make differences in thermal expansion coefficient between layers not to be a problem. It also allows maximizing interlayer adhesion by ion mixing, and creating a graded interface between adjacent layers. The only limitation to 
the latter is that the minimum thickness of each individual layer must be greater than twice the projected range of the ions during the high voltage cycle of the process to guarantee differentiation between the layers.

TiC/ta-C multilayers prepared by filtered cathodic arc were developed and tested as protective coatings for wear applications(62). A cross section TEM image of such a multilayer is shown in Figure 15. In addition, the elemental composition map obtained by electron energy filtered imaging is shown in Figure 16, where the concentration of the element indicated is proportional to the brightness in the image. Wear tests performed on such layers showed a remarkable difference depending on whether the first layer on the work-piece was $\mathrm{TiC}$ or $\mathrm{DLC}(89)$. The one with $\mathrm{TiC}$ at the interface failed massively with formation of cracks and debris. The DLC-TiC-DLC showed no sign of degradation beyond 50000 revolutions.

\section{SUMMARY}

The effect of using energetic particles (ions and atoms) during thin film deposition is remarkable. This warrants the use of ion energy and flux important parameters to tailor the microstructure and properties of thin films. Several materials can only be produced using energetic condensation processes, such as non-hydrogenated amorphous carbon with high content of $\mathrm{sp}^{3}$ bonding. In addition energetic deposition can lead to the improvement of properties of films that could be otherwise produced by other techniques. In particular, the field of superhard materials has greatly benefited from energetic deposition processes. One of the important advantages of energetic condensation is that 
the substrate temperature can be maintained very low without a negative effect on for instance adhesion. This is particularly important for deposition on substrates that are temperature sensitive, such as polymeric materials.

The combined effect of process parameters such as substrate temperature and ion energy is not fully understood, and it is expected that it will be material dependent. Therefore, although some broad considerations can be made, there is still a lot to be investigated for the specific materials systems of interest. MePIIID seems to be a valuable technique to be used to those who are willing to undertake this challenge, because it is fact a truly energetic deposition process with independent control of ion energy and fluxes, as opposed to conventional IBAD.

\section{Acknowledgments:}

I would like to thank all my co-workers for the last several years. I am particularly thankful to the Plasma Applications group staff at LBNL for all the support and fruitful discussions. This work was supported in part by the U.S. Department of Energy under contract number DE-AC03-76SF00098. 


\subsection{References}

1. Movchan BA, Demchishin AV. Fizika Metallov i Metallovedenie 28: 653 (1969)

2. Thornton JA. J. Vac. Sci. Technol. 11: 666 (1974)

3. Bunshah RF. J. Vac. Sci. Technol. 11: 633 (1974)

4. $\quad$ Dirks AG, Leamy HJ. Thin Solid Films 47: 219 (1977)

5. $\quad$ Leamy HJ, Dirks AG. Journal of Applied Physics 49: 3430 (1978)

6. Movchan BA, Demchishin AV. Phys. Met. Metallogr. 28: 83 (1969)

7. Messier R, Giri AP, Roy RA. J. Vac. Sci. Technol. A, 2: 500 (1984)

8. Cuomo JJ, Rossnagel SM, Kaufman HR. Handbook of Ion Beam Processing Technology. Mill Road: Noyes Publications (1989)

9. Machlin ES. Materials Science in Microelectronics: The Relationship between Thin Film Processing and Structure. Croton-on-Hudson: Giro Press (1995)

10. Olbrich W, Kampschulte G. Surf. Coatings Technol. 61: 262 (1993)

11. Kelly PJ, Arnell RD. Journal of Vacuum Science \& Technology A (Vacuum, Surfaces, and Films) 16: 2858 (1998)

12. Boyd KJ, et al. Journal of Vacuum Science \& Technology a-Vacuum Surfaces and Films 16: 463 (1998)

13. Lifshitz Y, Kasi SR, Rabalais JW. Phys. Rev. Lett. 62: 1290 (1989)

14. Lifshitz Y, Kasi SR, Rabalais JW, Eckstein W. Phys. Rev. B 41: 10468 (1990)

15. Brown IG. Ann. Rev. Mater. Sci. 28: 243 (1998)

16. Anders A, et al. J. Vac. Sci. Technol. B 12: 815 (1994)

17. Baglin JEE. In Fundamentals of Adhesion, ed. L-H Lee. New York: Plenum Publishing (1991) 
18. Baglin JEE. IBM J. Res. Develop. 38: 413 (1994)

19. Biersack JP, Haggmark LG. Nucl. Instr. Methods 174: 257 (1980)

20. Biersack JP. Nucl. Instr. Methods B19/20: 32 (1987)

21. Seitz F, Koehler JS.,, pp. 307 . New York: Academic Press Inc. (1956)

22. Dobrev D. Thin Solid Films 92: 41 (1982)

23. Ensinger W, Kiuchi M, Satou M. Journal of Applied Physics 77: 6630 (1995)

24. Ensinger W. Nucl. Instrum. Methods Phys. Res. B, Beam Interact. Mater. B106: $142(1995)$

25. McKenzie DR, et al. In Surface science. Principles and current applications, ed. RJ MacDonald, EC Taglauer, KR Wandelt, pp. 250. Berlin, Germany: SpringerVerlag (1996)

26. McKenzie DR, Bilek MMM. J. Vac. Sci. Technol. A 16: 2733 (1998)

27. McKenzie DR, Bilek MMM. Journal of Applied Physics 86: 230 (1999)

28. Doerner MF, Nix WD. CRC Critical Reviews in Solid State and Materials Sciences 14: 225 (1988)

29. Doljack FA, Hoffman RW. The origins of stress in thin nickel films. Presented at International Conference on Thin Films, Venice, Italy (1972)

30. Was GS, et al. Residual stress contorl by ion bema assisted deposition. Presented at Symposium Ion-Solid Interactions for Materials Modification and Processing. Symposium, Boston, MA, USA (1995)

31. Windischmann H. Journal of Applied Physics 62: 1800 (1987)

32. Windischmann H. Critical Reviews in Solid State and Materials Sciences 17: 547 (1992) 
33. Blanchard JP. J. Vac. Sci. Technol. B, 12: 910 (1993)

34. MacGill RA, et al. Rev. Sci. Instrum. 69: 801 (1998)

35. Monteiro OR, Wang Z, Hou PY, Brown IG. Nucl. Instrum. Meth. B 127/128: 821 (1997)

36. Monteiro OR, Zhi W, Brown IG. J. Mater. Res. 12: 2401 (1997)

37. Boxman RL, Goldsmith S. IEEE Trans. Plasma Sci. 17: 705 (1989)

38. Zhitomirsky VN, et al. Influence of gas pressure on the ion current and its distribution in a filtered vacuum arc deposition system. Presented at 23rd International Conference on Metallurgical Coatings and Thin Films, San Diego, CA, USA (1996)

39. Bilek MMM, Martin PJ, McKenzie DR. J. of Appl. Phys. 83: 2965 (1998)

40. Musil J, et al. Surf. Coat. Technol. 43-44: 259 (1990)

41. Pappas DL, Saenger KL, Cuomo JJ, Dreyfus RW. J. App. Phys. 72: 3966 (1992)

42. Pappas DL, et al. J. Appl. Phys. 71: 5675 (1992)

43. Voevodin AA, et al. J. Vac. Sci. Technol. A 14: 1927 (1996)

44. McKenzie DR, et al. Thin Solid Films 206: 198 (1991)

45. McKenzie DR, Muller D, Pailthorpe BA. Phys. Rev. Lett. 67: 773 (1991)

46. Fallon PJ, et al. Phys. Rev. B 48: 4777 (1993)

47. Falabella S, Boercker DB, Sanders DM. Fabrication of amorphous diamond films. Presented at 20th International Conference on Metallurgical Coatings and Thin Films, San Diego, CA, USA (1993)

48. Lifshitz Y, et al. Diamond Rel. Mater. 3: 542 (1994)

49. Lifshitz Y, et al. Diamond Rel. Mater. 4: 318 (1995) 
50. Uhlmann S, Frauenheim T, Lifshitz Y. Phys. Rev. Lett. 81: 641 (1998)

51. Lifshitz Y. Diamond and Related Materials 8: 1659 (1999)

52. Robertson J. Diamond and Related Materials 2: 984 (1993)

53. Pharr GM, et al. Appl. Phys. Lett. 68: 779 (1996)

54. Anders S, et al. Presented at Symposium Mechanical Behavior of Diamond and Other Forms of Carbon. Symposium, San Francisco, CA, USA (1995)

55. McKenzie DR, et al. Diamond and Rel. Mater. 1: 51 (1991)

56. $\quad$ Peng XL, Clyne TW. Diamond and Related Materials 7: 944 (1998)

57. Friedmann TA, et al. Appl. Phys. Lett. 68: 1643 (1996)

58. Friedmann TA, et al. Appl. Phys. Let.t. 71: 3820 (1997)

59. Anders S, et al. Appl. Phys. Lett. 71: 3367 (1997)

60. Monteiro OR, et al. Journal of Applied Physics 88: 2395 (2000)

61. Ager JW, III, et al. Surface and Coatings Technology 91: 91 (1997)

62. Delplancke-Ogletree MP, Monteiro OR, Brown IG. Preparation of TiC and TiC/DLC multilayers by metal plasma immersion ion implantation and deposition: relationship between composition, microstructure and wear properties. Presented at Symposium Materials Modification and Synthesis by Ion Beam Processing. Symposium, Boston, MA, USA (1996)

63. Dimigen H, Klages CP. Surface \& Coatings Technology: 543 (1991)

64. Ullmann J. Low energy ion assisted carbon film growth: methods and mechanisms. Presented at Tenth International Conference on Ion Beam Modification of Materials, Albuquerque, NM, USA (1996) 
65. Ullmann J, Heger P, Pinkert K, Baba K. Ions as a useful tool for carbon film deposition and modification. Presented at Ninth International Conference on Ion Beam Modification of Materials, Canberra, ACT, Australia (1995)

66. Ullmann J, Baba K, Martin H, Wolf GK. Effect of deposition conditions on the growth and behaviour of thin carbon films prepared by ion-assisted evaporation. Presented at Fourth International Conference on Plasma Surface Engineering, Garmisch-Partenkirchen, Germany (1994)

67. Jun Q, et al. Surface and Coatings Technology 128-129: 324 (2000)

68. Salvadori MC, Galvao RM, Monteiro OR, Brown IG. Thin Solid Films 325: 19 (1998)

69. Sridharan K, et al. In Handbook of Plasma Immersion Ion Implantation and Deposition, ed. A Anders, pp. 553. New York: John Wiley adn Sons (2000)

70. Cuomo JJ, et al. Journal of Applied Physics 70: 1706 (1991)

71. Lee DH, Misra A, Waiter KC, Nastasi M. Physical Review B (Condensed Matter) 59: 12283 (1999)

72. McKenzie DR, et al. J. Non-Cryst. Solids 164-166: 1101 (1993)

73. Anders S, et al. Thin Solid Films 308 - 309: 186 (1997)

74. Kalish R, Lifshitz Y, Nugent K, Prawer S. Appl. Phys. Lett. 74: 2936 (1999)

75. Voevodin AA, et al. Applied Physics Letters 69: 188 (1996)

76. Voevodin AA, Prasad SV, Zabinski JS. Journal of Applied Physics 82: 855 (1997)

77. Delplancke-Ogletree MP, Monteiro OR. J. Vac. Sci. Technol. A 15: 1943 (1997)

78. Monteiro OR, et al. Surf. Coatings Technol. 94/95: 220 (1997) 
79. Zhao JF, et al. J. Phys.: Condens. Matter 12: 9201 (2000)

80. Pierson HO. Handbook of Refractory Carbides and Nitrides: Properties, Characteristics and Applications. Westwood: Noyes Publications (1996)

81. Barret C, Massalski TB. Structure of Metals: Pergamon Press (1980)

82. Delplancke MP, Vassileris V, Winand R. Structure and composition of hydrogenated $\mathrm{Ti} / \mathrm{sub} \mathrm{x} / \mathrm{C} / \mathrm{sub} \mathrm{y} /$ thin films prepared by reactive sputtering. Presented at 41st National Symposium of the American Vacuum Society, Denver, CO, USA (1994)

83. Wolfe DE, Singh J. Surface and Coatings Technology 124: 142 (2000)

84. Voevodin AA, O'Neill JP, Prasad SV, Zabinski JS. Journal of Vacuum Science \& Technology A (Vacuum, Surfaces, and Films) 17: 986 (1999)

85. Monteiro OR, le Delplancke-Ogletree MP, Brown IGG. Thin Solid Films 342: 100 (1999)

86. Davis CA. Thin Solid Films 226: 30 (1993)

87. Voevodin AA, Erokhin AL, Lyubimov VV. Phys. Status Solidi A 145: 565 (1994)

88. Anders S, et al. Multilayers of amorphous carbon prepared by cathodic arc deposition. Presented at 24th International Conference on Metallurgical Coatings and Thin Films, San Diego, CA, USA (1997)

89. Delplancke-Ogletree MP, Monteiro OR. Wear behavior of diamond-like carbon/metal carbide multilayers. Presented at 25th International Conference on Metallurgical Coatings and Thin Films, San Diego, CA, USA (1998) 


\section{List of Fgures}

Figure 1: Microstructure zone model for ion beam assisted deposition (after Messier et $\left.\mathrm{al}^{7}\right)$

Figure 2(a): Cross-section high-resolution transmission electron image of the interface between $\mathrm{Si}$ and $t a-\mathrm{C}$ (DLC) prepared with $2 \mathrm{keV} \mathrm{C}^{+}$ions and duty cycle of $25 \%$.

Figure 2(b): Monte-Carlo simulation of Si and C profiles after deposition of DLC with 2 $\mathrm{keV} \mathrm{C}^{+}$ions and duty cycle of $25 \%$.

Figure 3: Correlation between intrinsic stress and incident ion energy for a metallic film produced by ion beam assisted deposition.

Figure 4: Schematic representation of the thermal balance during energetic deposition.

Figure 5: Schematic representation of Metal Plasma Ion Immersion Implantation and Deposition process

Figure 6: Density of DLC films prepared by filtered cathodic vacuum arc as a function of the $\mathrm{C}^{+}$ion energy

Figure 7: Calculated temperature evolution of a thin $\mathrm{Si}$ substrate during deposition of DLC film.

Figure 8: Hardness of DLC films for different total energy deposited onto the films

Figure 9: Bright-field image of DLC:Ti prepared with ion current ratio C:Ti 25:3

Figure 10: High resolution TEM of TiC

Figure 11: Electron diffraction pattern of titanium carbon films prepared ion current ratios $\mathrm{C}: \mathrm{Ti}$ (a) 25:3 and (b) 5:3 
Figure 12: Electron diffraction pattern od tungsten carbon films with $20 \% \mathrm{~W}$ (a) and $7 \%$ W (b)

Figure 13: Hardness of DLC:W films prepared by filtered cathodic vacuum arc as a function of $\mathrm{W}$ content different bias voltages

Figure 14: Intrinsic stress of DLC:W films prepared by filtered cathodic vacuum arc as a function of $\mathrm{W}$ content different bias voltages

Figure 15 Cross- section transmission electron micrograph in bright field of a DLC-TiC multilayer

Figure 16: Composition map of DLC:TiC multilayer. 


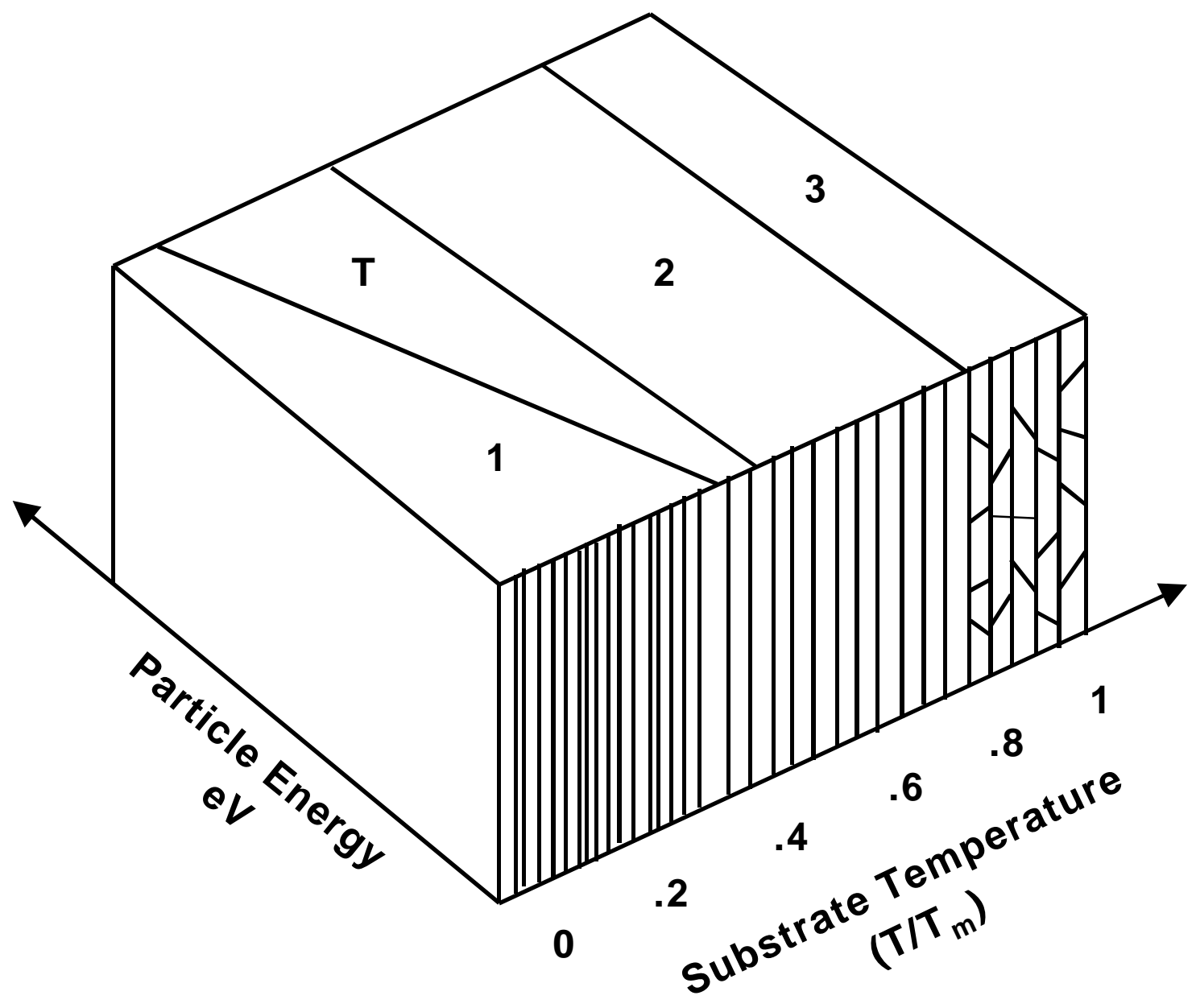

Figure 1 


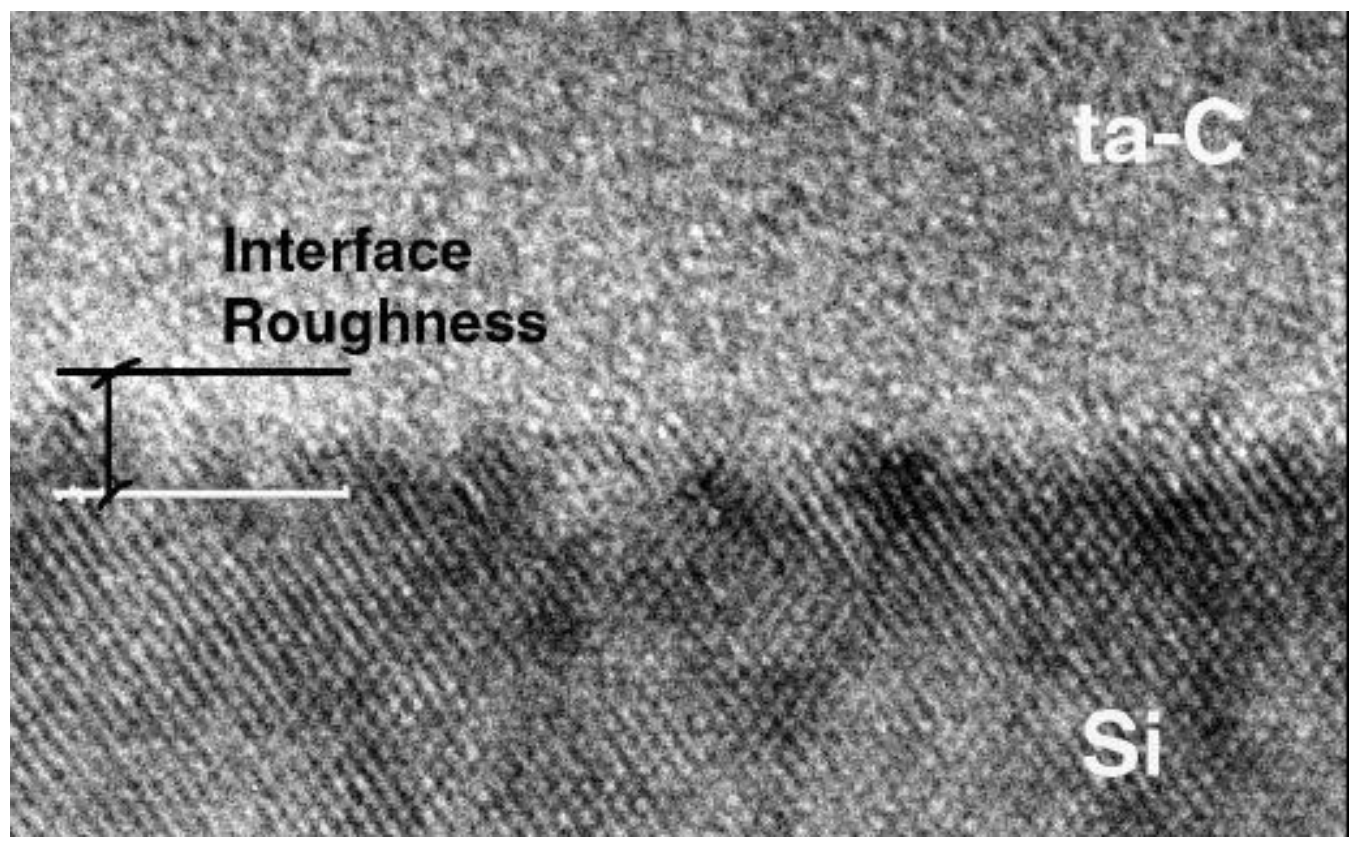

Figure 2 


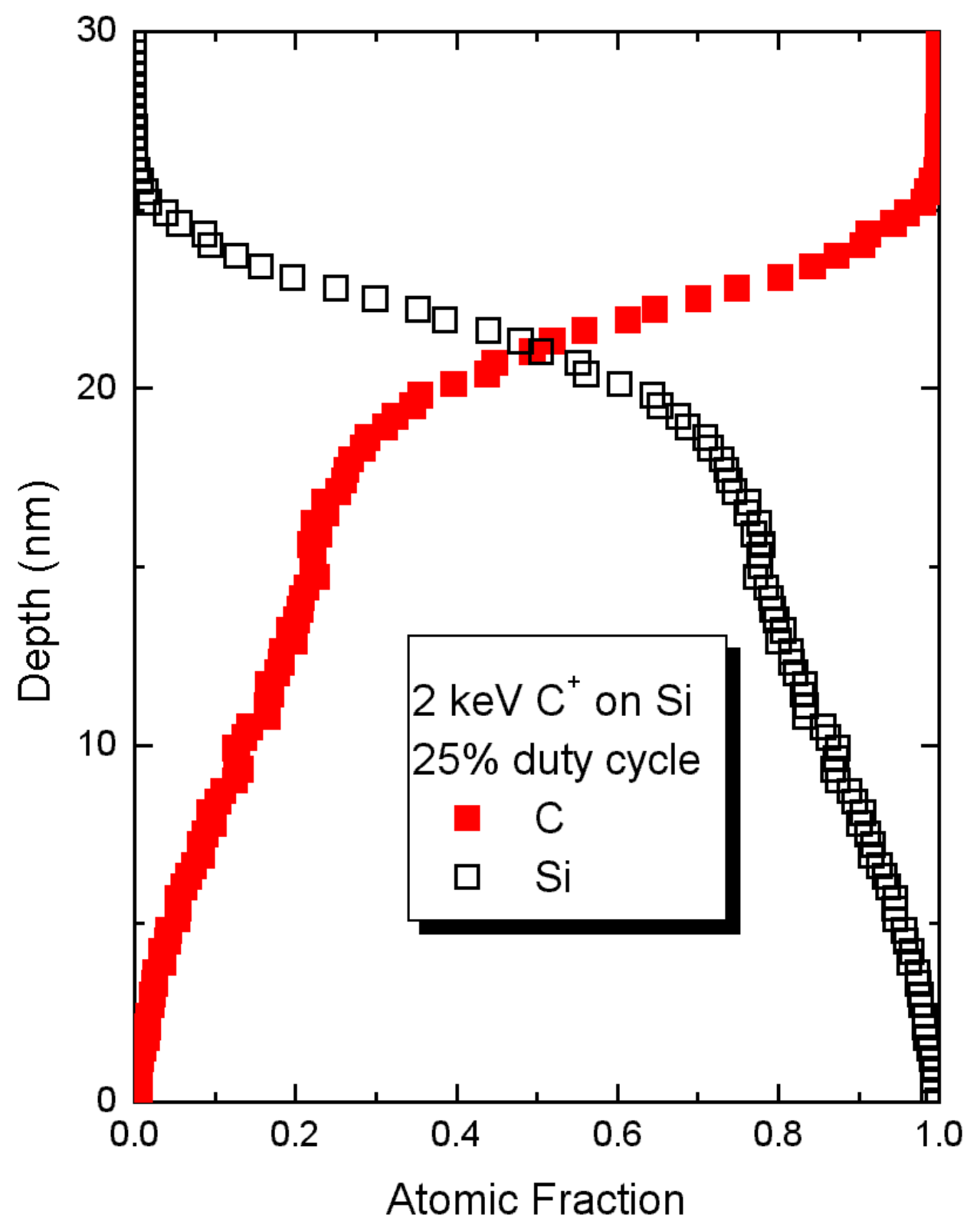

Figure T-dyn interface 


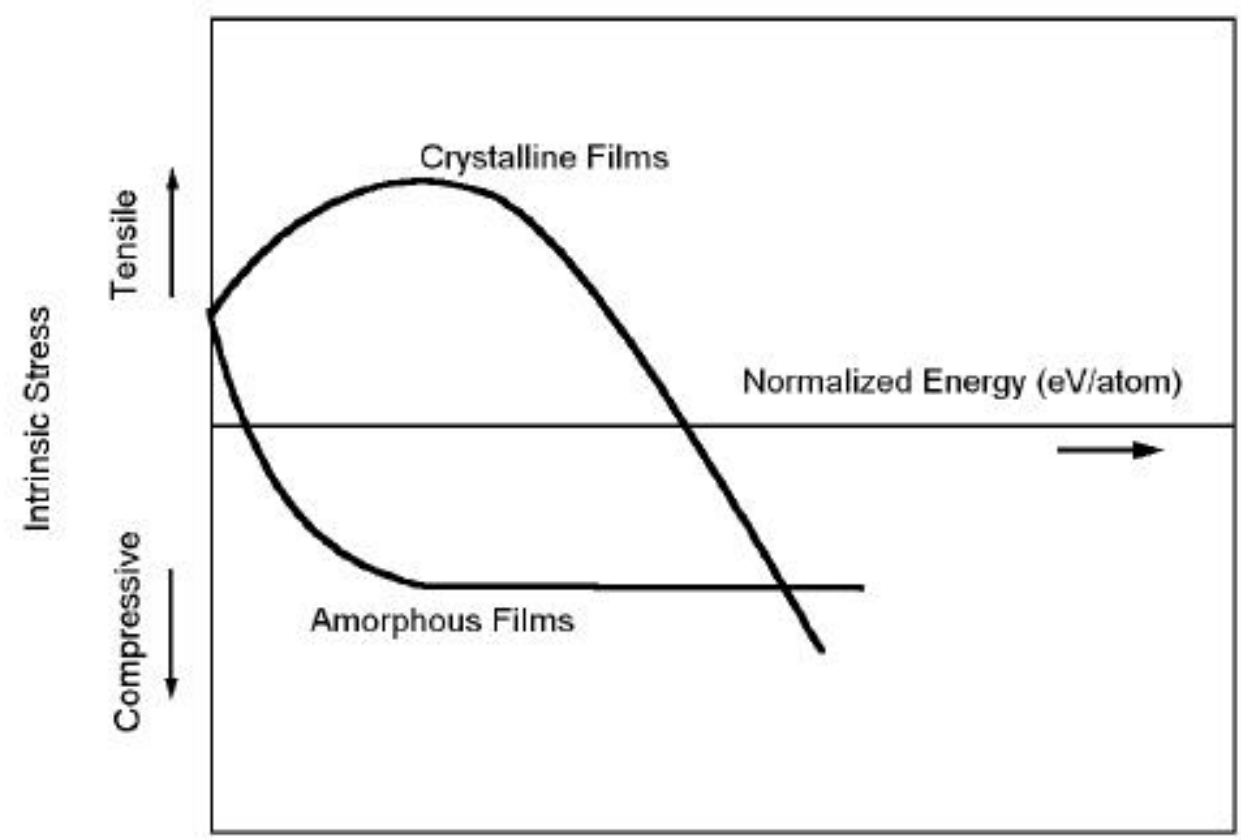

Figure (GenericStress), 


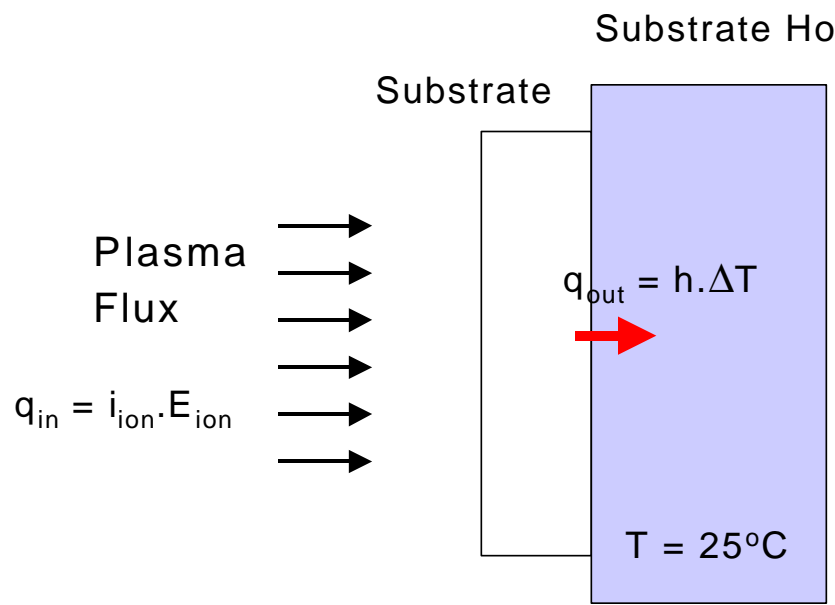

Figure (thermal balance) 
(a)

(b)

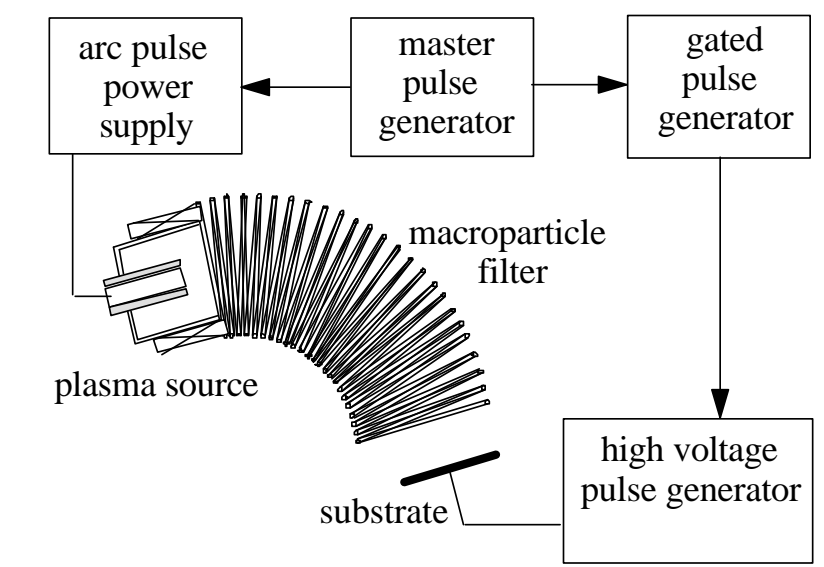

b)

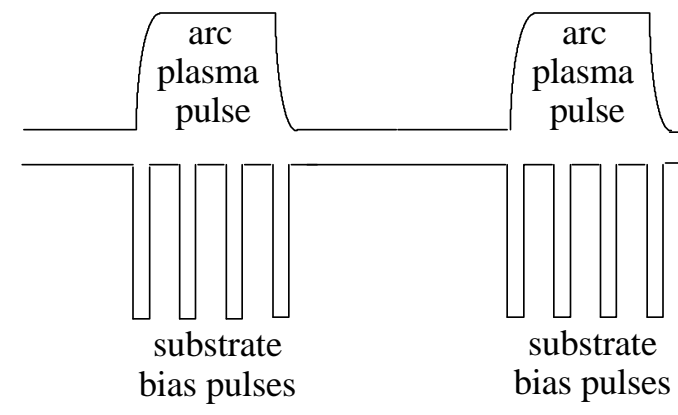

Figure (Apparatus) 


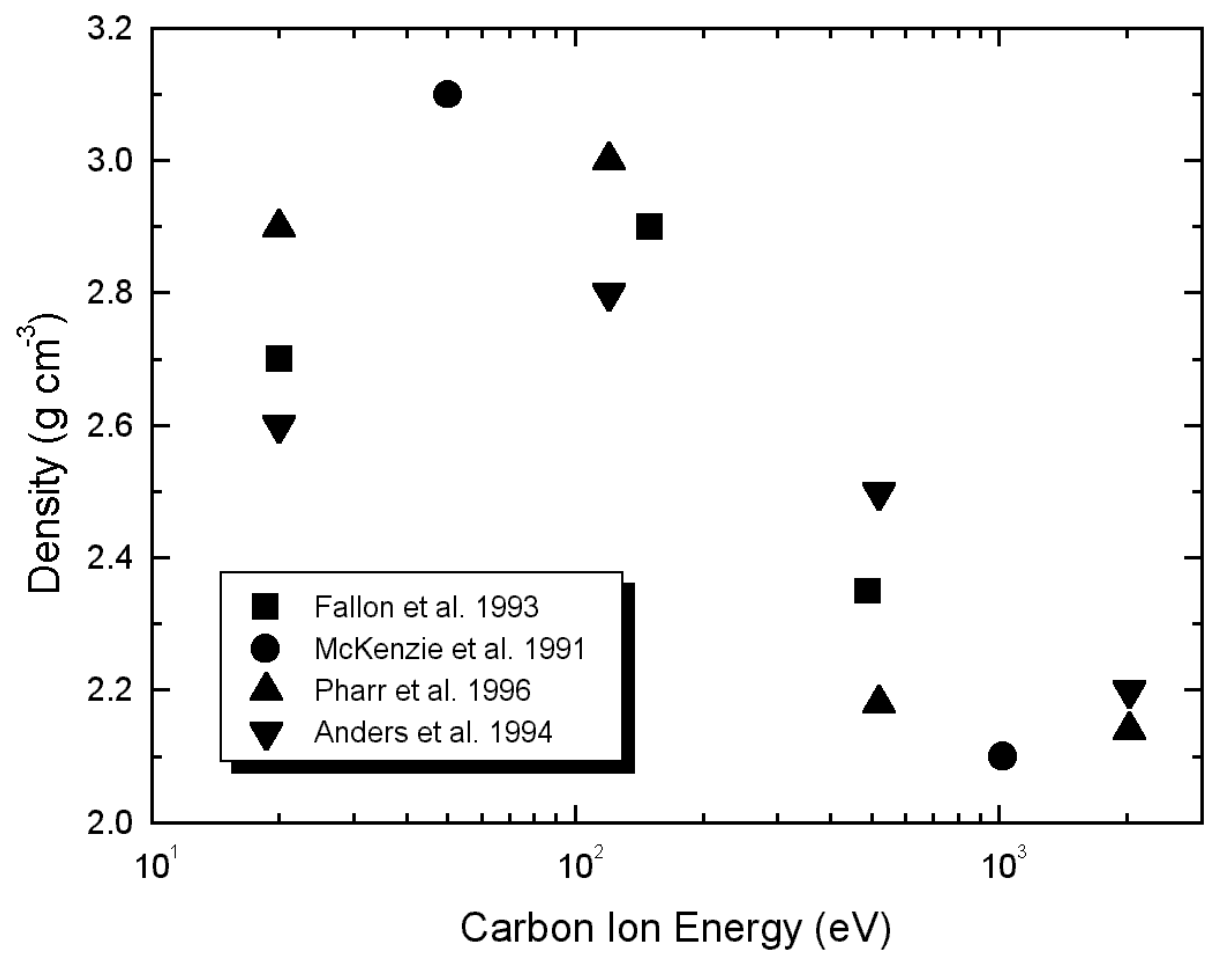

Figure (DLC-Properties). 


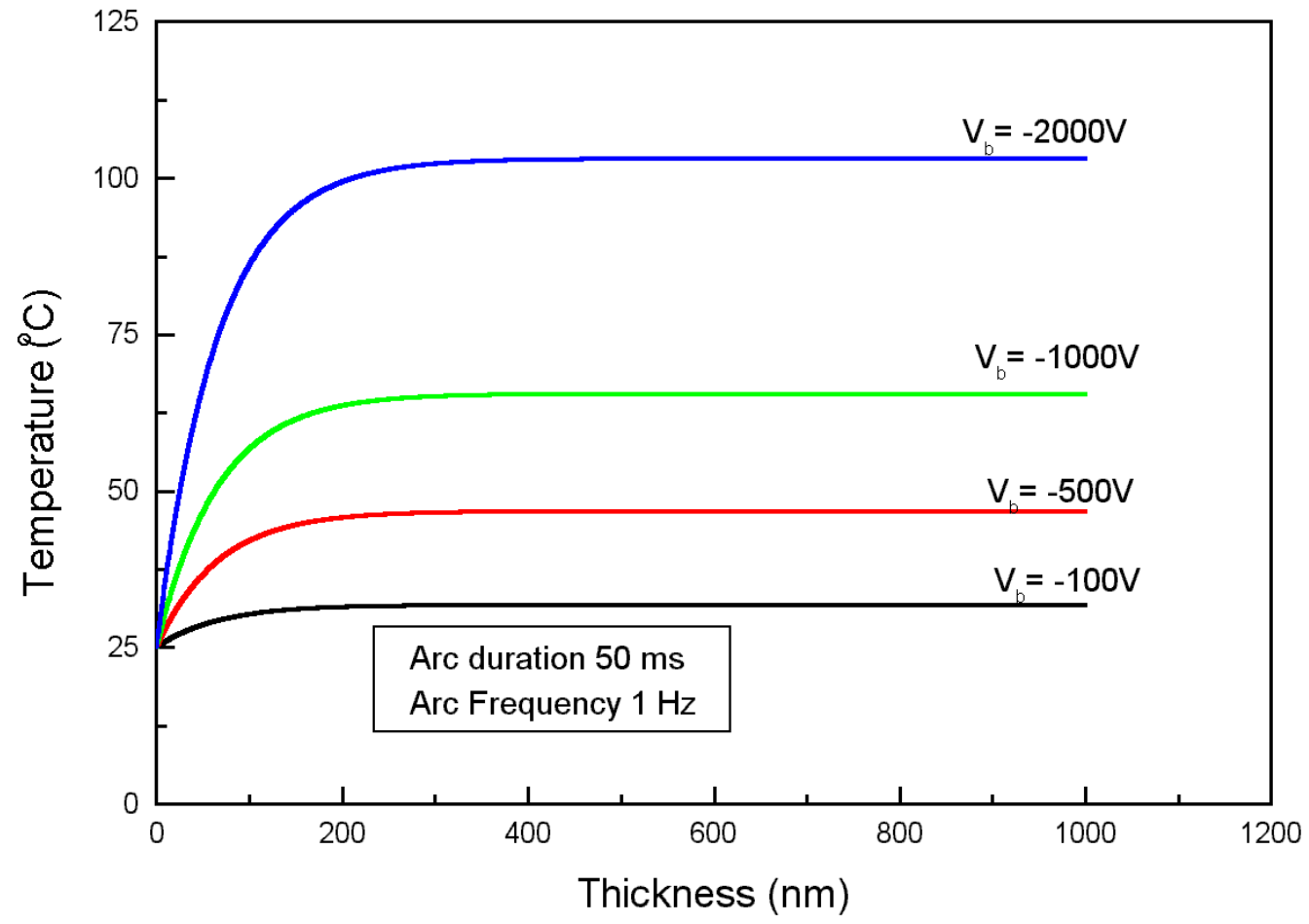

Figure Temperature evolution 


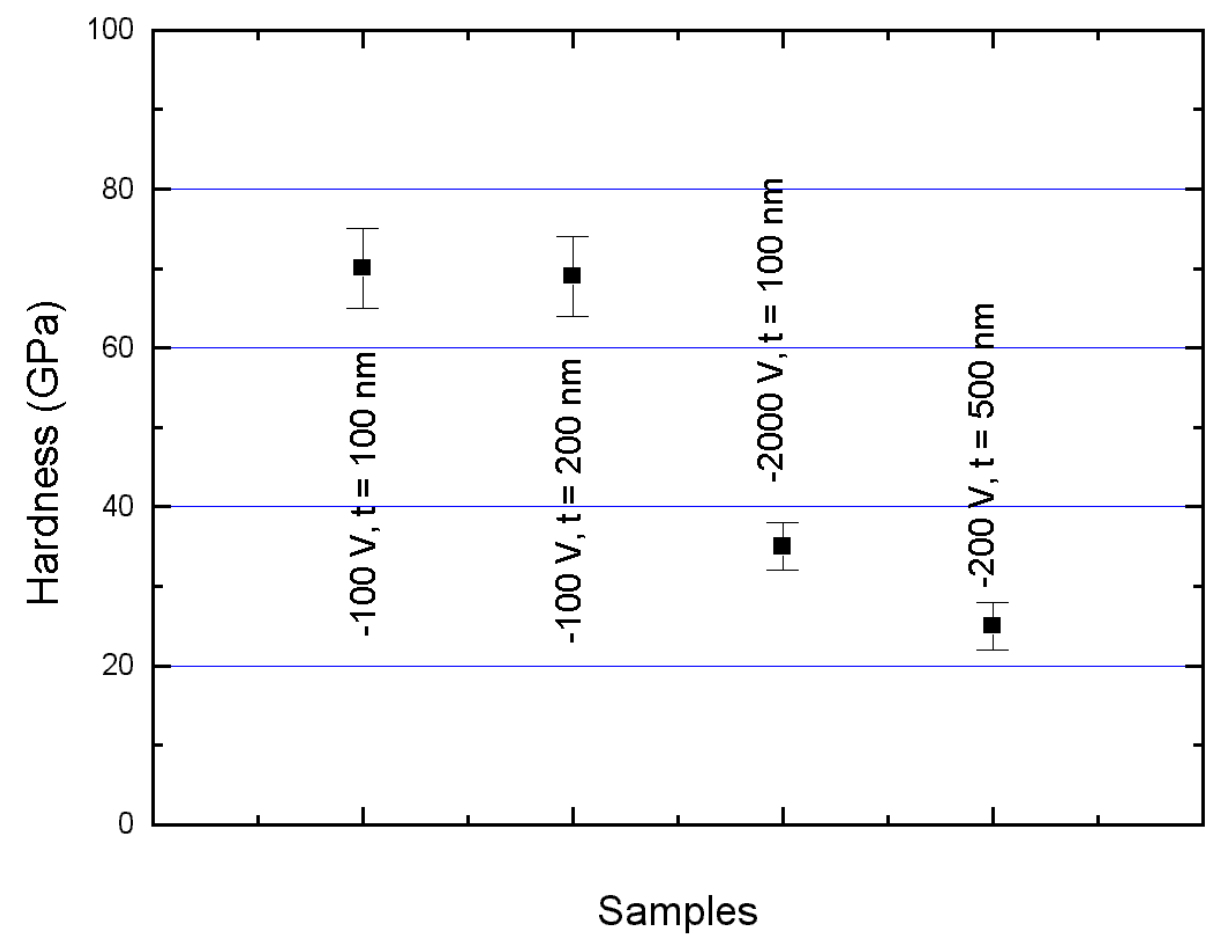

Figure TEMP-HARD-HISTORY 


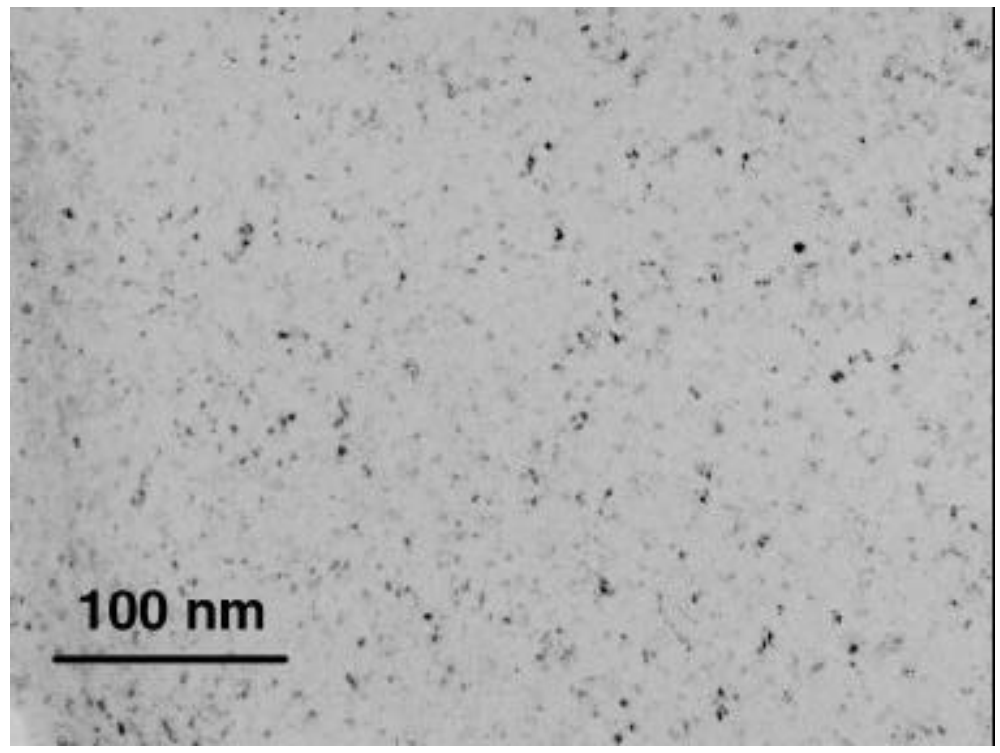

Figure TEM-BF-TiC 


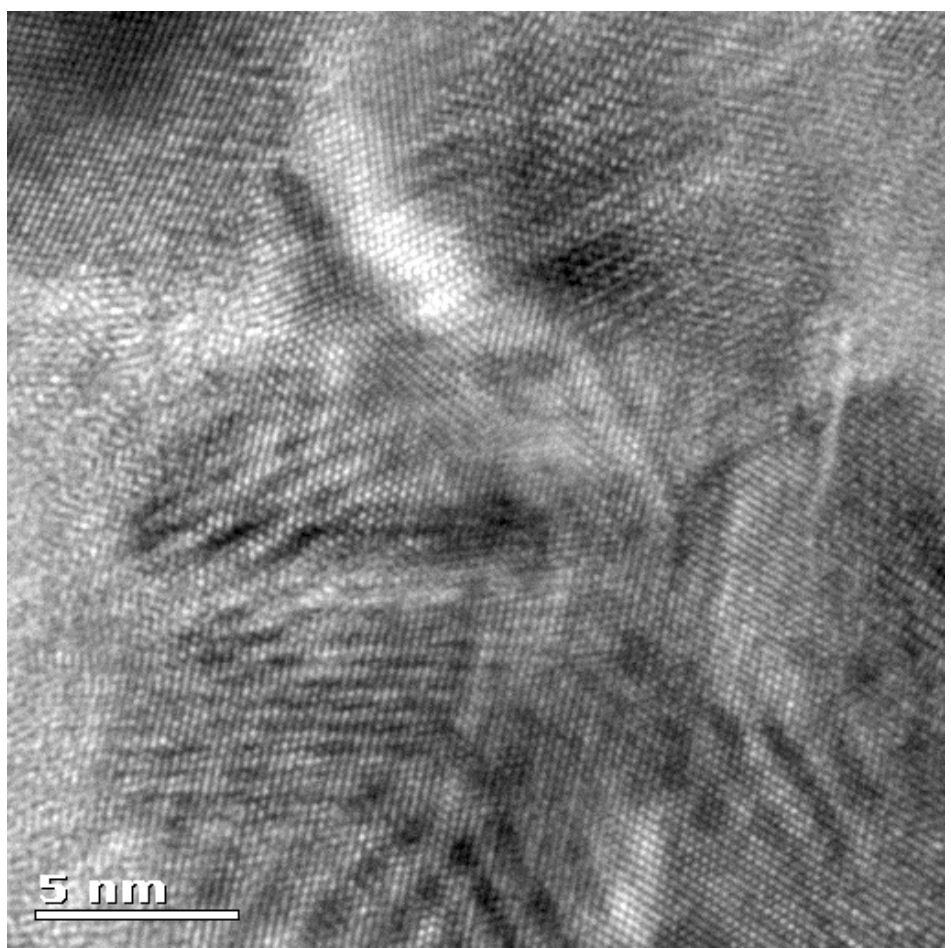

Figure HR-TEM-TiC 


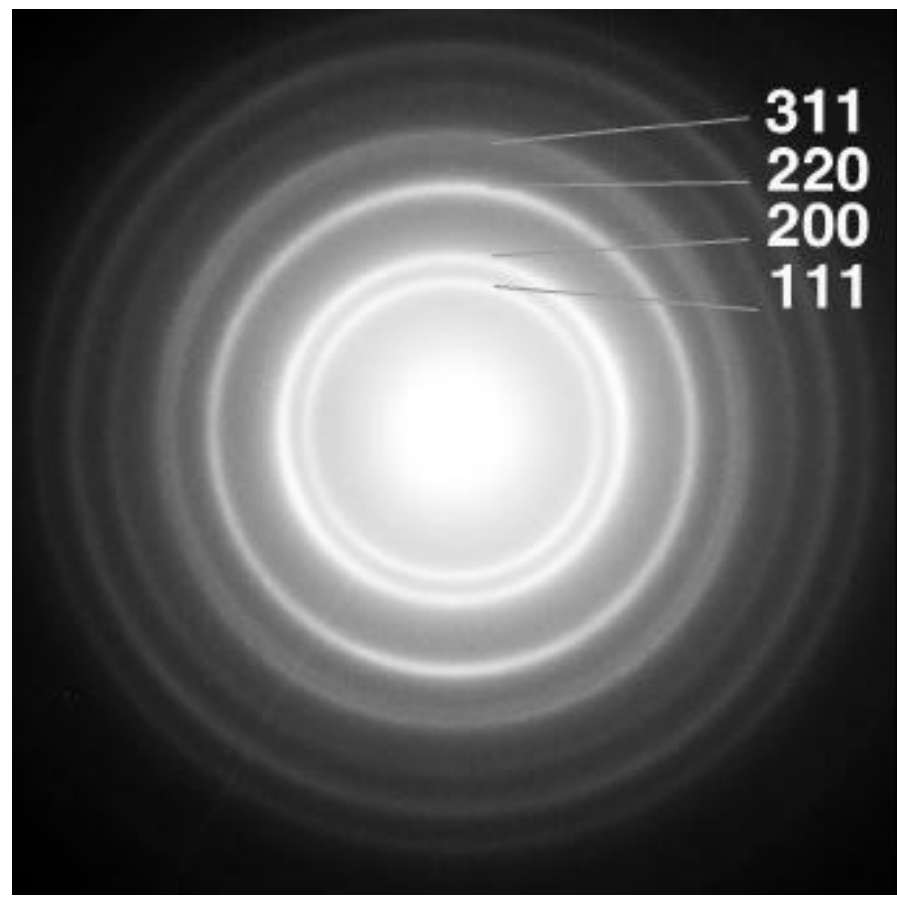

(a)

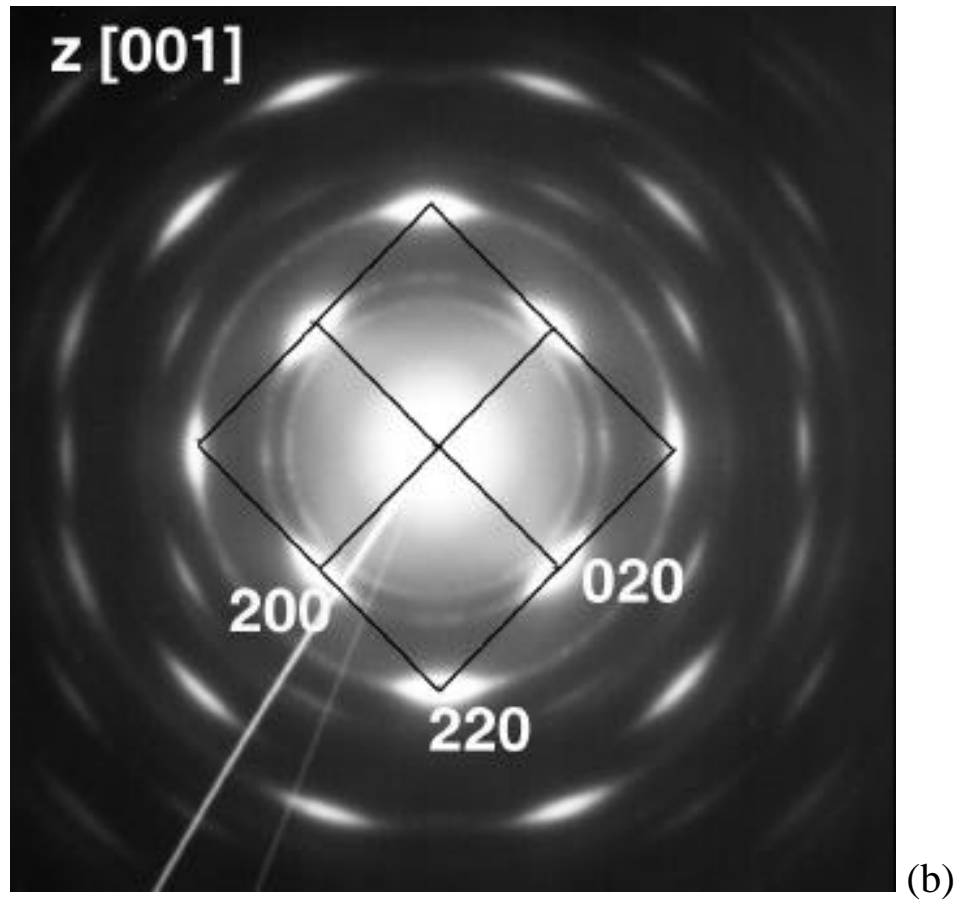

Figure TEM-TiC-DP 

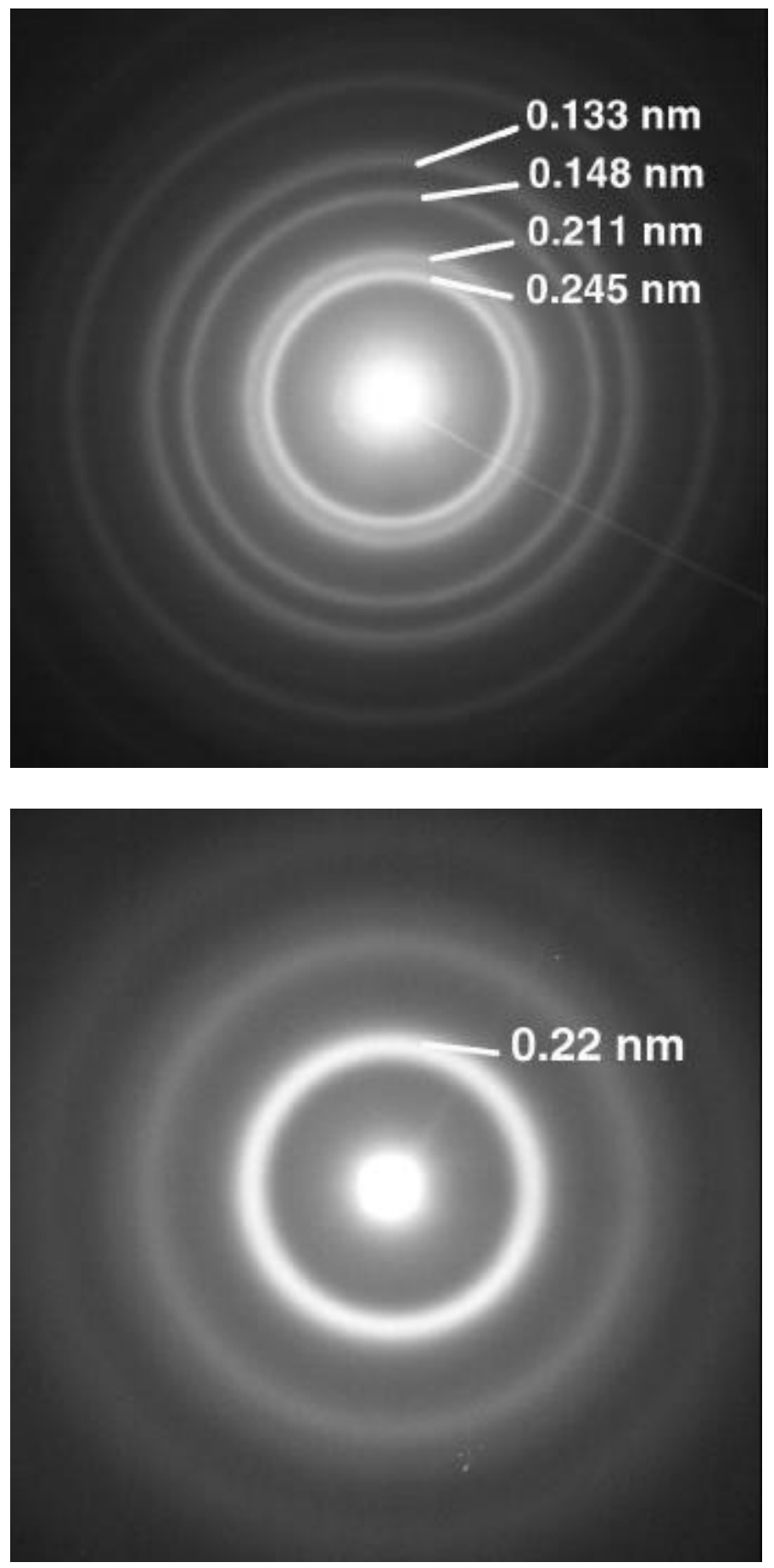

Figure TEM-WC-DP 


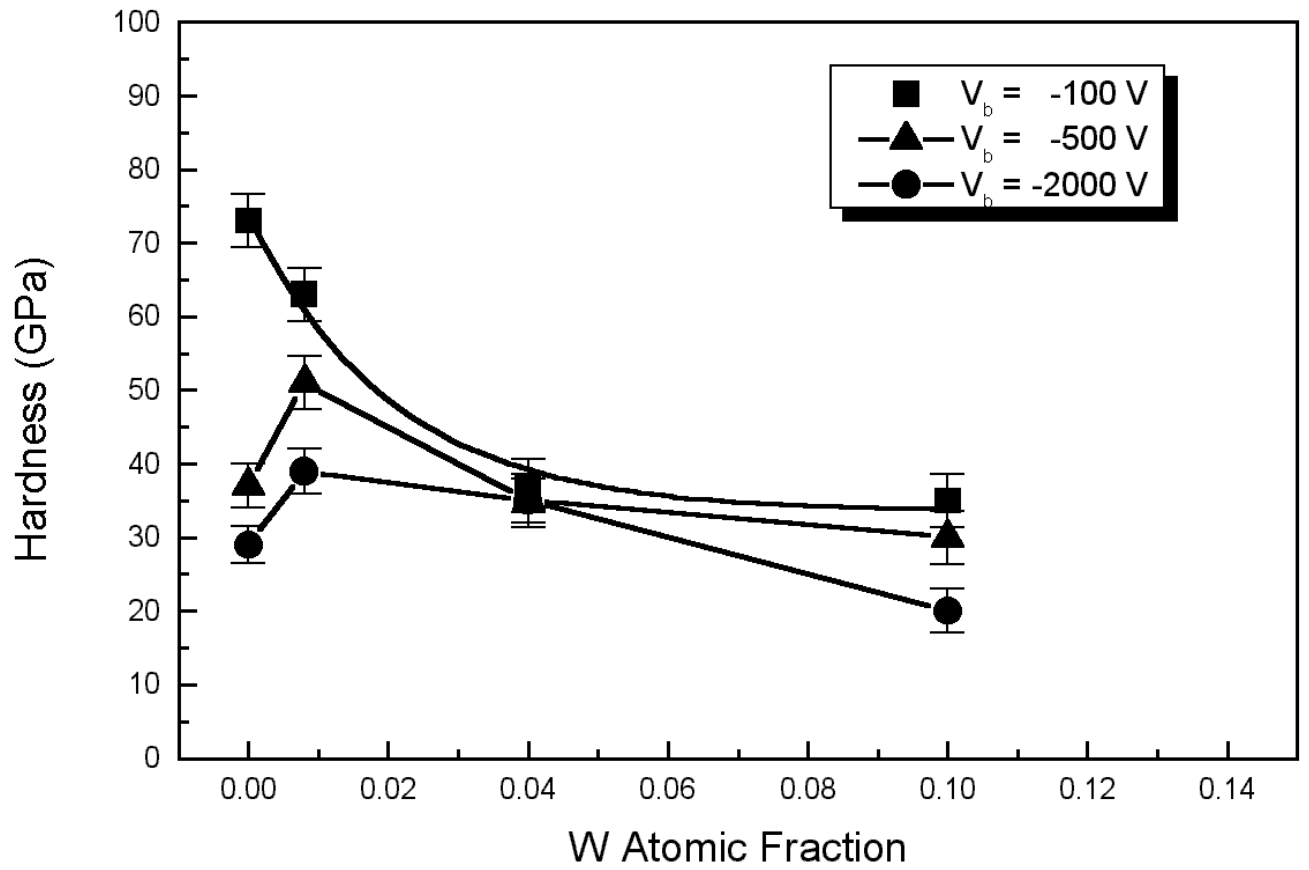

Figures (Hardness DLC:W) 


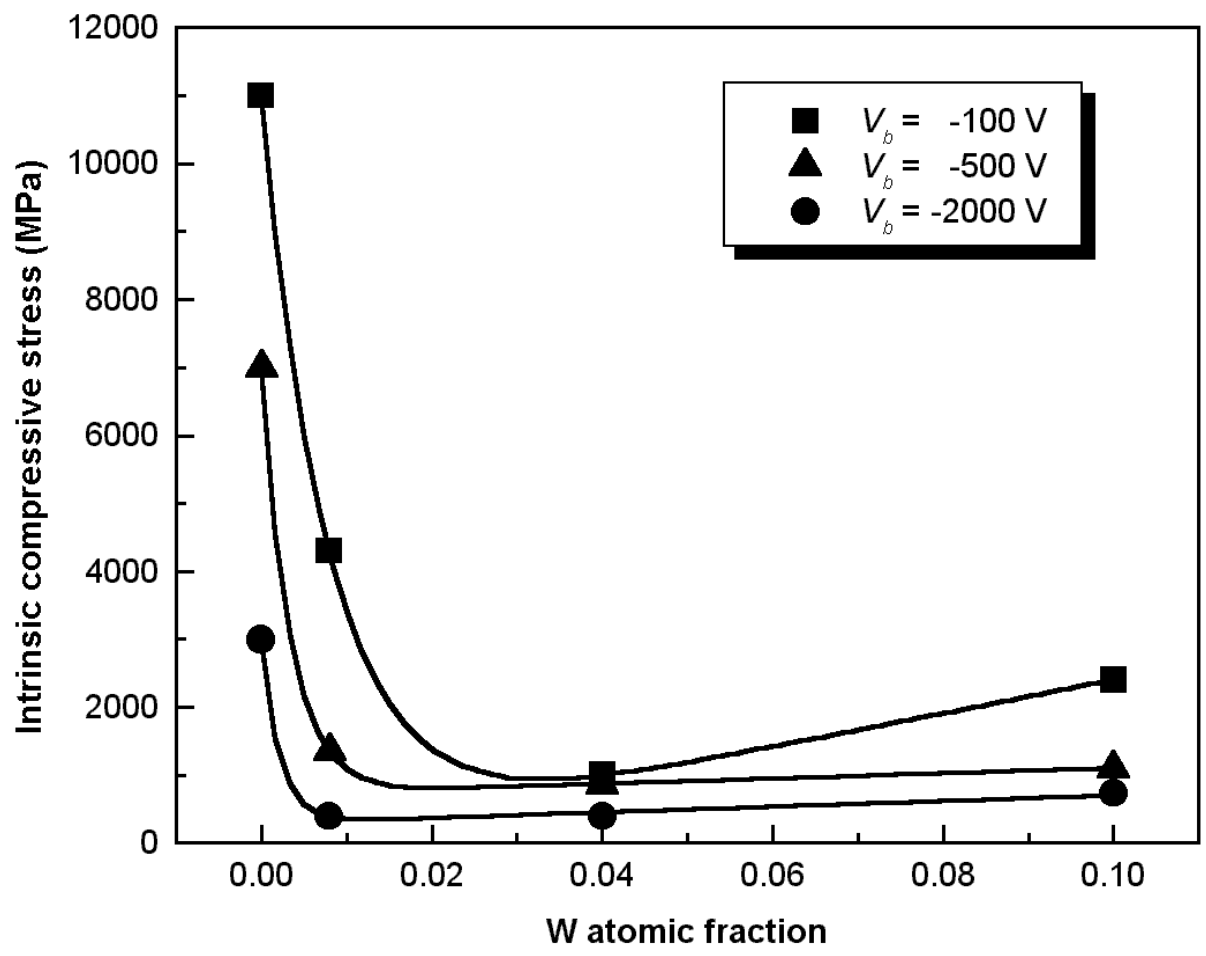

Figure (Stress-DLC:W) 


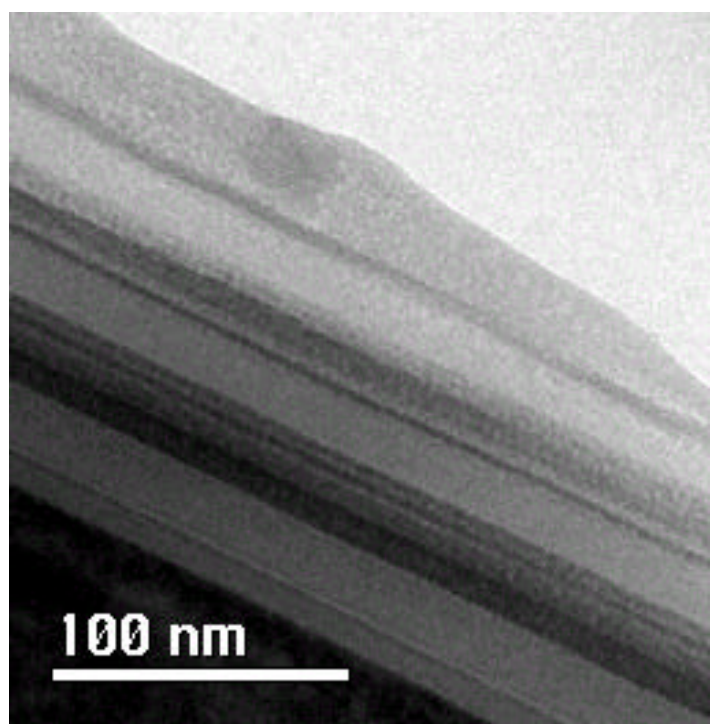

Figure (XTEM-TiC-DLC)

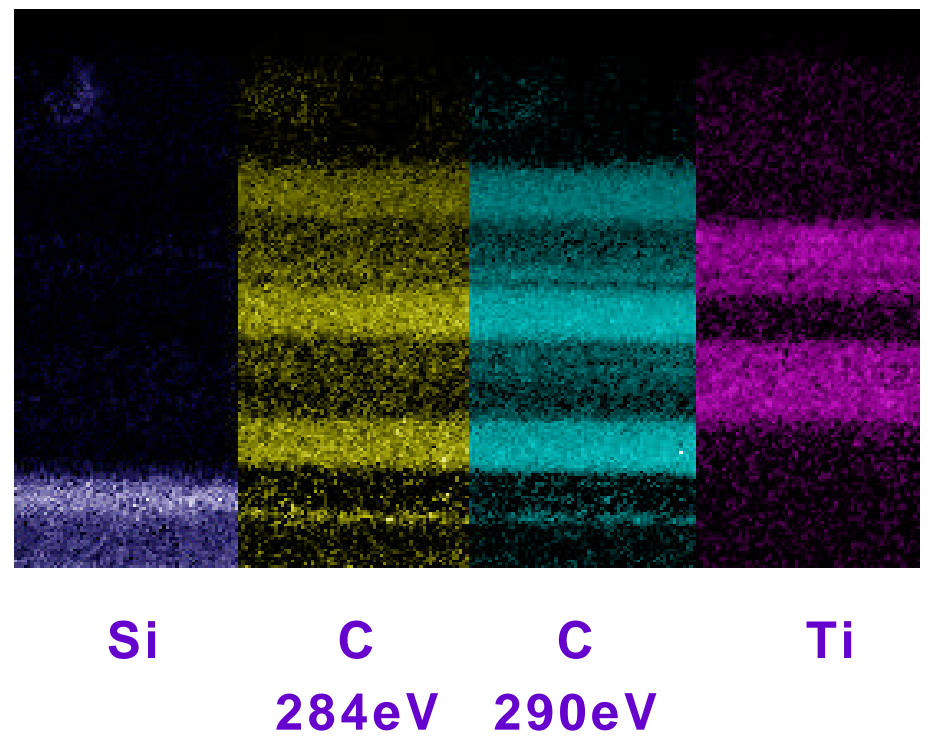

Figure (XTEM-TiC-DLC-Map) 